\title{
3D Seismic Reflection Data Analysis in Part of Niger-Delta Basin, Nigeria
}

\author{
Olatunbosun L.G ${ }^{1, *}$, E.O. UKO ${ }^{2}$, K.A.J. Gbadegesin ${ }^{1}$ \\ ${ }^{1}$ Department of Science Technology, Federal Polytechnic, Ado-ekiti, Ekiti State, Nigeria \\ ${ }^{2}$ Department of Physics, Rivers State University of Science and Technology, Nigeria
}

Copyright $(\subset 2015$ by authors, all rights reserved. Authors agree that this article remains permanently open access under the terms of the Creative Commons Attribution License 4.0 International License

\begin{abstract}
Seismic reflection data obtained from 3D survey in part of the Niger-Delta basin, Nigeria was processed using Velocity Computation Software program (VELCOM), an interactive velocity analysis interpretation program. The application uses the principle of Apparent Velocity Picking, Normal Moveout (NMO) Correction and Stacking. Velocity intervals for 8 Common Depth Points (CDPs) were obtained. Interval velocity ranges between 1814 and $5579 \mathrm{~ms}^{-1}$ and Stacking velocity $\left(\mathrm{V}_{\mathrm{s}}\right)$ ranges between 1814 - $3639 \mathrm{~ms}^{-1}$. Both velocities increase with depth, where interval velocity is more steeply than stacking velocity within the same interval depth. The result of this velocity analysis can be applied in NMO correction, calculating depths from reflection times, horizons identifications, the recognitions of lithology, detection of high pressure zone and migration.
\end{abstract}

Keywords Velocity, Seismic Reflection, Normal Moveout

\section{Introduction}

The earth subsurface consists of several layers that contribute reflections to a single seismogram. Seismic reflection surveying is the most widely used geophysical technique. This is because, seismic reflection data permits mapping of many horizons or layers with each shot. The basic principle of seismic reflection technique is to generate seismic waves and measure the time taken for the waves to travel from the source, reflect off an interface and be detected by an array of receivers (geophones) at the surface [1]. The knowledge of travel times from the source to various receivers and the velocity of the seismic waves, the pathways of the waves can be constructed to build an image of the subsurface. Multiples from the bottom of a body of water and the air-water interface are common in marine seismic data (which is not desirable), and are suppressed by seismic processing.

Velocity analysis is an area of Geophysics which has attracted the attention of the processors and the end users over the years since the introduction of the reflection method of seismic data. The curvature of the alignments that could be seen on the field records was indicative of the delays undergone by the waves as they traveled through the earth. This is as a result of some factors, such as, the type of rock, the porosity of the formation, density of the rock, materials filling the rock pores, the depth of burial of the rock and the pressure on the rock. It therefore became necessary to derive relationships between travel times and the acoustic velocities of the layers which comprise the earth. The implications of these analyses are firstly, that the wavelets have reflection complexes and secondly, that there will always be a variation of velocity as a new geological sequence is entered.

In this work, 3D seismic reflection data was analyzed to get the different seismic velocities, which are the basis of hydrocarbon exploration. A principal use of velocity functions derived from reflection velocity analyses is the correction of primary reflections in each common depth point (CDP) trace gather for NMO prior to residual static time correction and trace summation (stacking). The knowledge of the true interval velocity of each layer is needed in the hydrocarbon industry.

\section{Geology of the Study Area}

The Niger Delta situated at the west African margin of the Gulf guinea, is a large arcuate delta, which occupies an area located between longitude $4^{\circ}$ and $9^{\circ} \mathrm{E}$ and $4^{\circ}$ and $6^{\circ} \mathrm{N}$ [2]. The geology of the area was controlled by three main tectonic phases: The first tectonic cycle is in the Albian resulted in the formation of the Benue and Abakiliki troughs and infilling by Albian shales and sandstones. This period also marked the establishment of the Calabar and Benin flanks. The second tectonic cycle was marked by the folding of sediments during the Santonian. This episode was followed by considerable magnetic activity and 
mineralization. The third cycle, the late Eocene led to the establishment of the modern Niger Delta [3]. Figure 1 shows the geological map of Niger Delta and its surroundings.

There exist three subsurface stratigraphic units in the modern Niger Delta: Benin, Agbada and Akata formations [4]. The Benin formation is the alluvial or upper coastal plain depositional environment of the Niger Delta Complex. It extends from the West Niger Delta area and to the South beyond the present coastline. The Benin formation consists of course-grained, gravelly sandstone with minor intercalation of shale. It is a continental deposit of Miocene to younger in age and has a thickness in excess of $1820 \mathrm{~m}$. Typical outcrops of the Benin formation can be seen around Benin, Onitsha and Owerri. The Agbada formation underlies the Benin formation. It was laid down in parallic brackish to marine fluviatile, coastal environments. The Agbada formation is made up primarily of alternating sandstones and shales and is of fluviomarine origin. It ranges in age from Eocene in the North to Pliocene in the South. These sands, sandstones and shales which make up the formation, attain a maximum thickness of about $4500 \mathrm{~m}$. The Agbada formation is time equivalent to the Asaba-Ameki formation further north. The Akata formation is the lowest unit of the Niger Delta Complex. It was deposited in a marine environment and the formation outcrops offshore in shale diapers [5]. Akata formation consists of shale with local interbedding of sands and sandstones. The formation becomes shalier with depth. The thickness may reach $7000 \mathrm{~m}$ in the central part of the delta. The Akata formation ranges from Eocene to Recent [4][6].

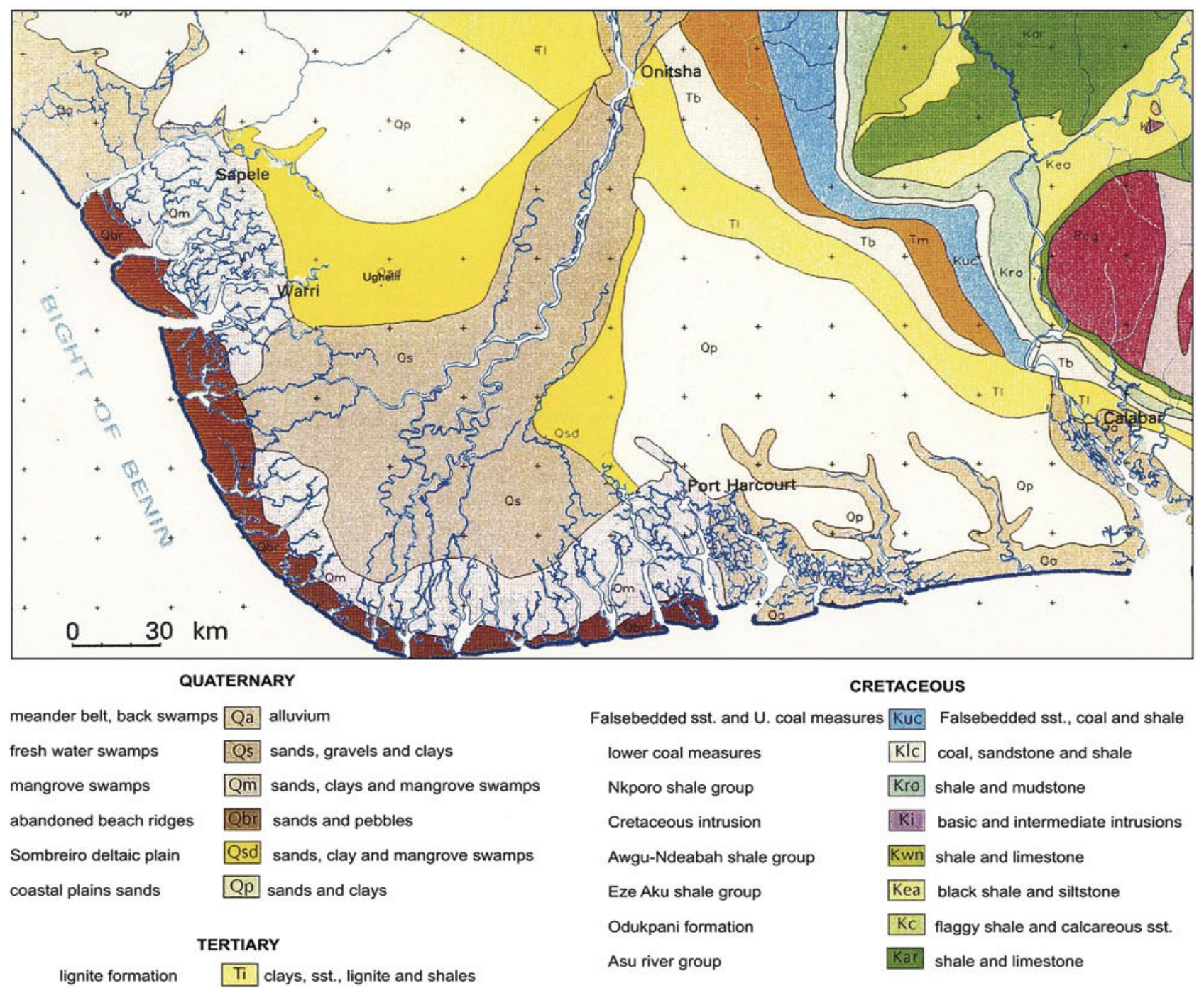

Bende Ameki group $\mathrm{Tb}$ clays, clayey sands and shale

PRE-CAMBRIAN TO UPPER CAMBRIAN

Imo clay-shale group $\mathrm{Tm}$ clays and shales with Ist.

basement complex $\mathrm{Pcg}$ older granite

Figure 1. Map of Niger Delta and its surroundings (Adapted from [7]) 


\section{Methodology}

The travel time, $\mathrm{t}$ at offset, $\mathrm{x}$ is assumed to relate to the zero - offset travel time, $\mathrm{t}_{\mathrm{o}}$ by:

$$
t^{2}=t_{o}^{2}+\frac{x^{2}}{V_{s}^{2}}
$$

where $\mathrm{V}_{\mathrm{s}}$ is the stacking velocity, approximately equal to the root mean square (RMS) average velocity to the reflector concerned. Determination of the NMO correction is therefore equivalent to analyzing the seismic velocity structure of the section. The value of $\mathrm{V}_{\mathrm{s}}$, when large volumes of data are involved requires an automated method rather than a plot of $t^{2}$ versus $x^{2}$, where $1 / V_{S}$ is the slope of the graph. In this case, the constant velocity stacks (CVS), which assumed that the seismic velocity has a constant specific value throughout the ray path was applied. This method was preferred because of its effect on noisy data. It enhances signal-to-noise ratio. The alignments across the gather are always difficult to see if signal to noise ratio is poor [8]. Calculation of NMO for each trace as a function of TWT (Two-Way-Time) can then be made. The traces of the gather are corrected for NMO using these calculated values. Where NMO has been correctly removed, a reflector will line up horizontally across the gather. If the true stacking velocity is less than that assumed in constructing the CVS, the event will be under corrected and will bend down towards the larger offset traces; if the true velocity is greater than that assumed, the event will be over-corrected and bend up at the larger offsets. Thus, the estimation of the TWT can be made successfully where the assumed velocity is equal to the desired stacking velocity.

An application, VELCOM was used in processing the 3D seismic reflection data obtained in part of Niger Delta Basin, Nigeria. This data consists of many thousands of shot records with many common depth points (CDPs). VELCOM is an interactive velocity analysis interpretation program. It enables the view of seismic data on the screen and performs interactive interpretation. Analysis locations and density are defined in the processing flow interactive monitoring and editing of the velocity field is performed with displays including in-line or cross-line isovelocities, constant - time and constant horizon - velocities. NMO can be applied any time to the current CDP gather, enabling check on the validity of the picks. VELCOM allows for pick shift or transverse isotropic picking and to perform both the shifted hyperbola and transverse isotropic NMO correction. VELCOM gave the stacking velocities. The interval velocities therefore were calculated from the Dix's expression [9].

$$
V_{i n}^{2}=\frac{V_{s n}^{2} t_{n}-V_{s n-1}{ }^{2} t_{n-1}}{t_{n}-t_{n-1}} .
$$

\section{Presentation, Interpretation and Results}

The Velcom ministack is made up of various CDP trace gathers (fig.2). It was composed of high quality reflections and contains the display of seismic traces of the central, uncorrected CDPs (fig.3). Apparent velocity picks were made and are shown on the spectrum and scale semblance profile (fig.4). The picks were made at the sharpest points of events and NMO correction applied using VELCOM application. The display then contains a seismic trace of the central, corrected CDP (fig.5). The NMO correction, which was applied, depends on the type of loaded data. The application (VELCOM) used the principle of constant velocity stack (CVS), which assumed that the seismic velocity has a constant specific value throughout the ray path. The calculation of NMO for each trace as a function of TWT (Two - Way - Time) was then made. The traces of the gather are corrected for NMO using these calculated values. Where NMO was correctly removed, a reflector will line up horizontally across the gather, as shown in fig. 5. If the true stacking velocity is less than that assumed in constructing the CVS, the event will be under corrected and will bend down towards the larger offset traces; if the true velocity is greater than that assumed, the event will be over-corrected and bend up at the larger offsets. Thus, the estimation of the TWT can be made successfully where the assumed velocity is equal to the desired stacking velocity. The principle of CVS was so chosen because it works better for noisy data. The alignments across the gather are always difficult to see if signal to noise ratio is poor.

VELCOM was aimed at getting the stacking velocity as displayed in the Velcom Isovel (fig.6). The Isovel displays the stacking velocities for eight CDPs of the same line after processing. The stacking velocities vary with time and increases with depth. The Velcom plots for different CDPs shown in figure 7, compared stacking and interval velocities in relation to zero- offset time. Stacking velocity increases with time in proportion, while that of interval velocity increases in a discrete manner. Both velocities also increase with depth, with interval velocity more steeply than stacking velocity within the same interval depth. 


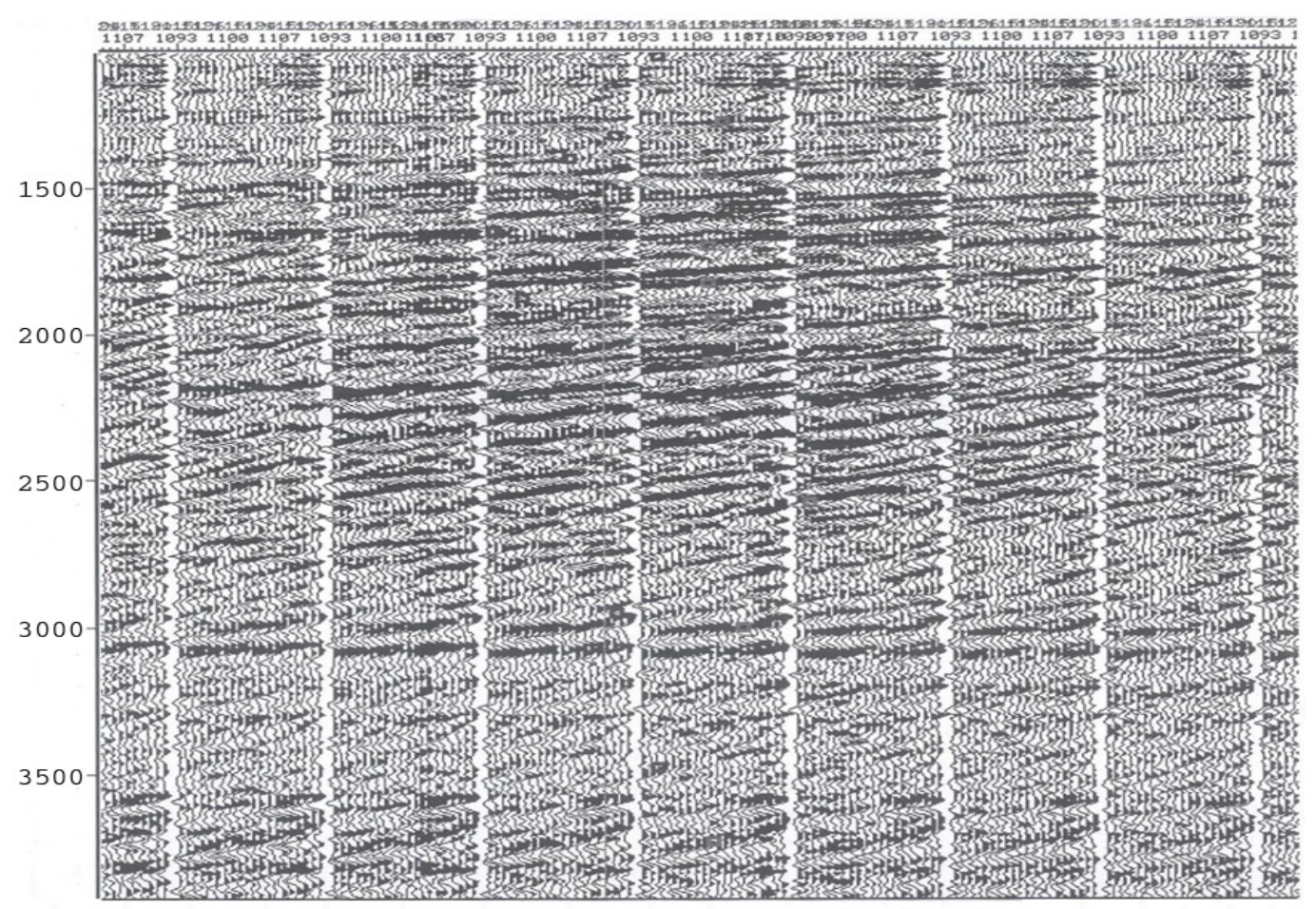

Figure 2. VELCOM MINISTACK, consisting of different CDPs of the same line

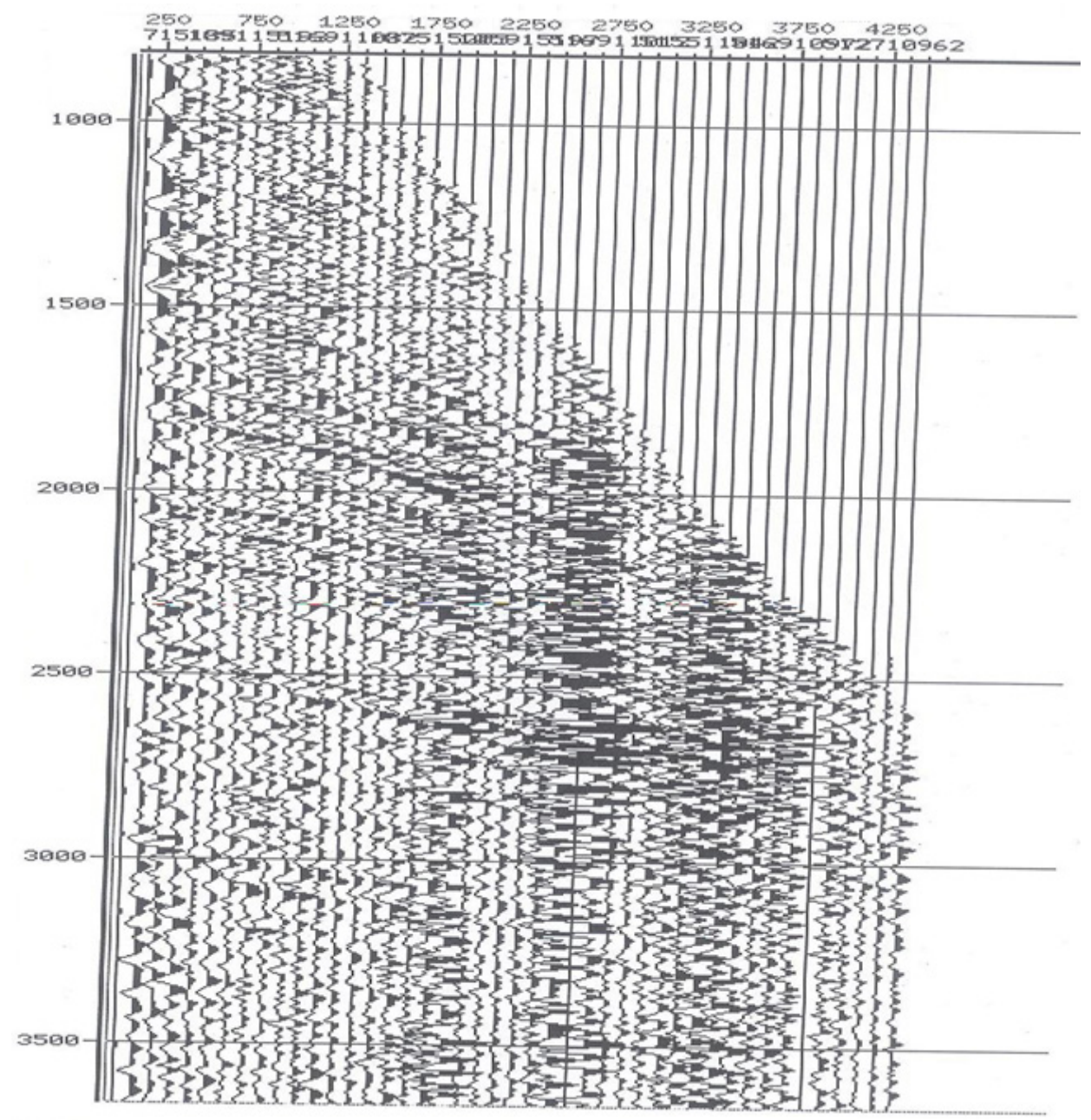

Figure 3. VELCOM CDP GATHER before NMO correction, showing the curvature of the alignments 


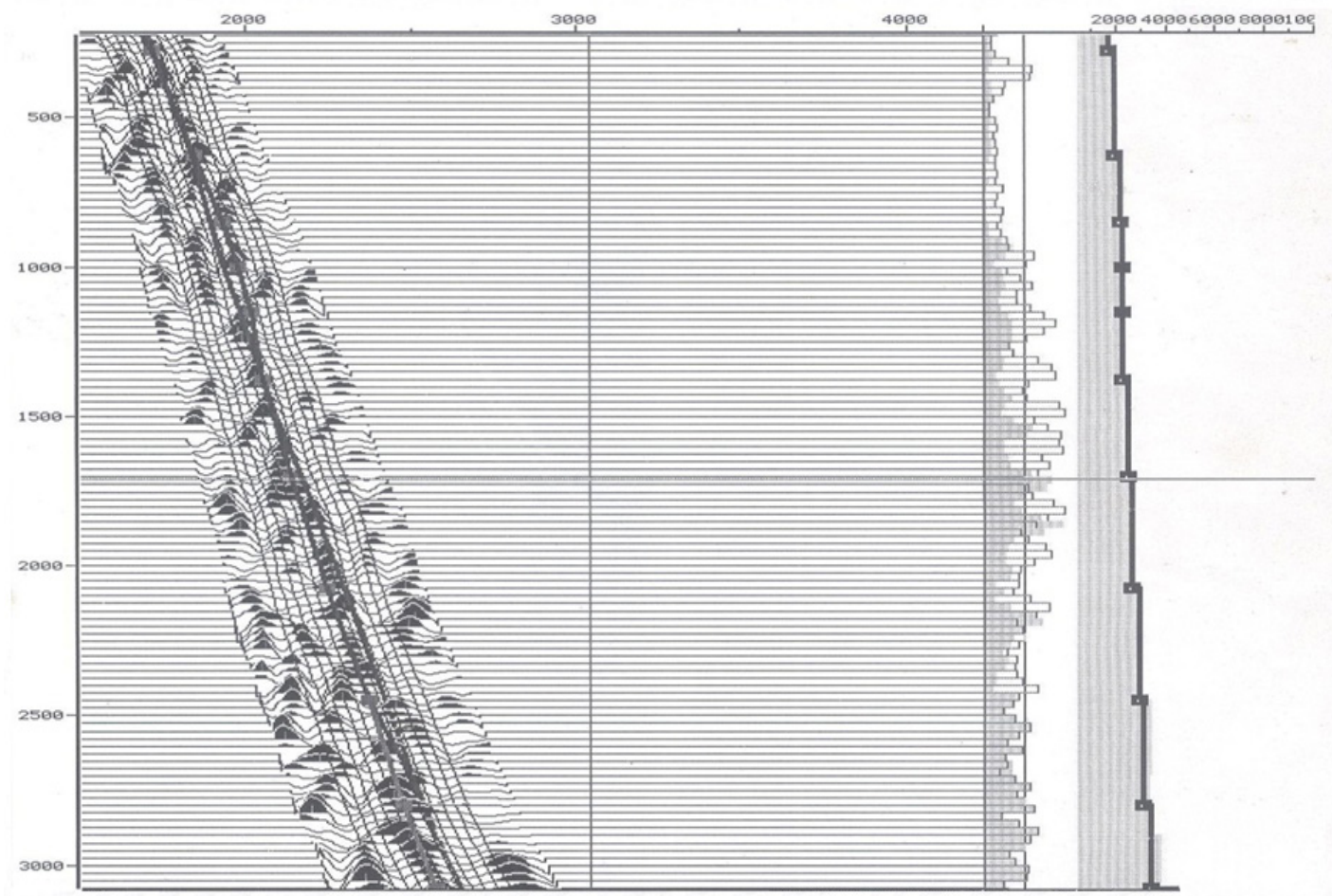

Figure 4. VELCOM SPECTRUM AND SCALE SEMBLANCE PROOFILE, showing the picks

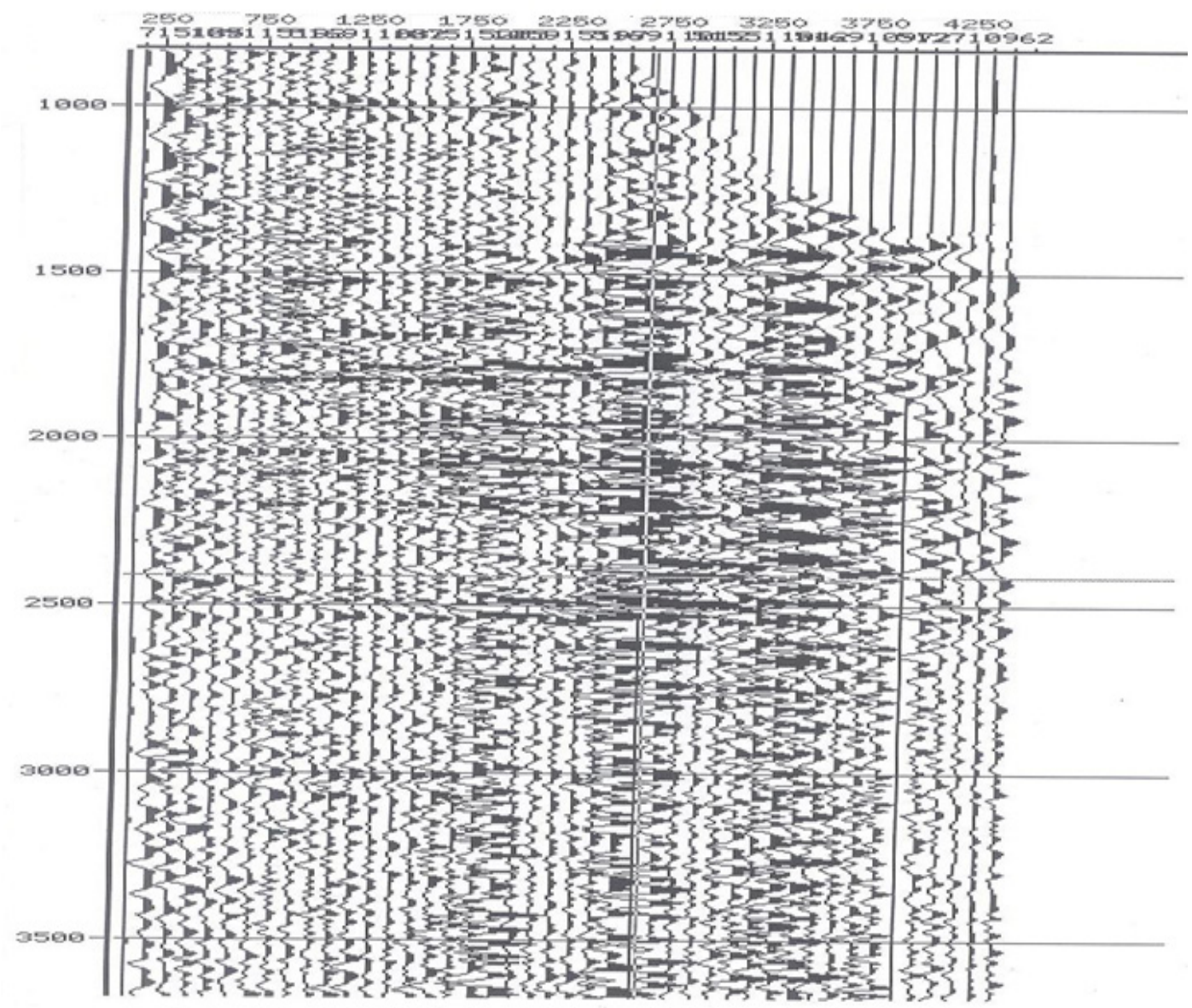

Figure 5. VELCOM CDP GATHER AFTER NMO CORRECTION, showing the horizontal alignments 


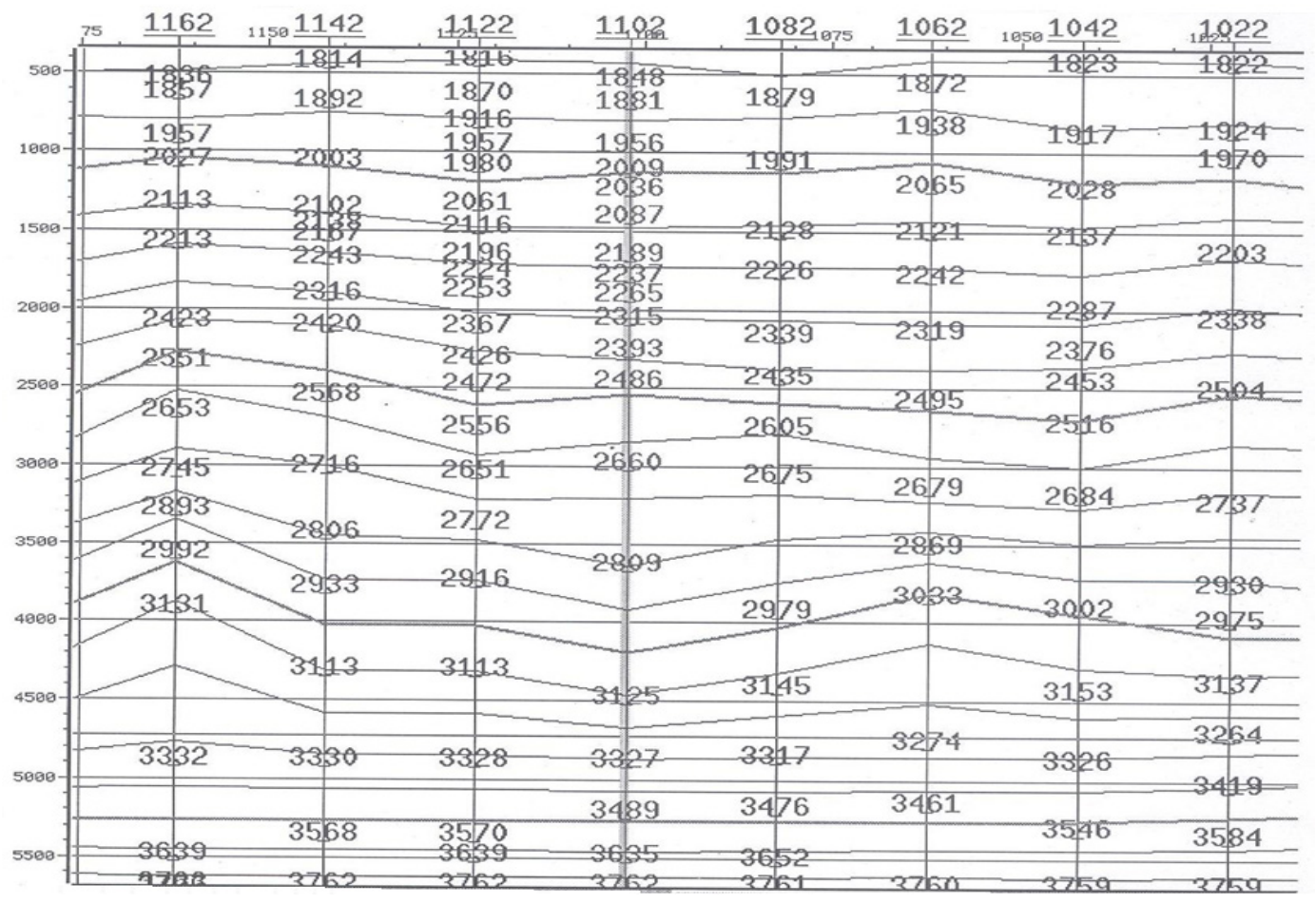

Figure 6. VELCOM ISOVEL, showing the variation of stacking velocities with time

CDP 1102

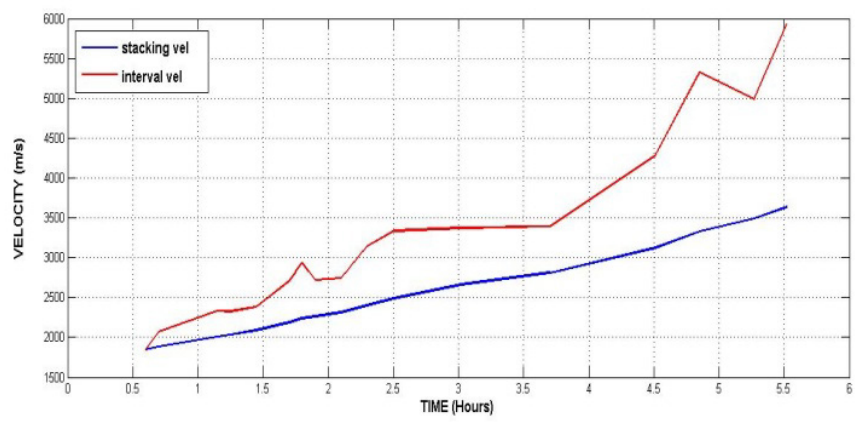

CDP 1122

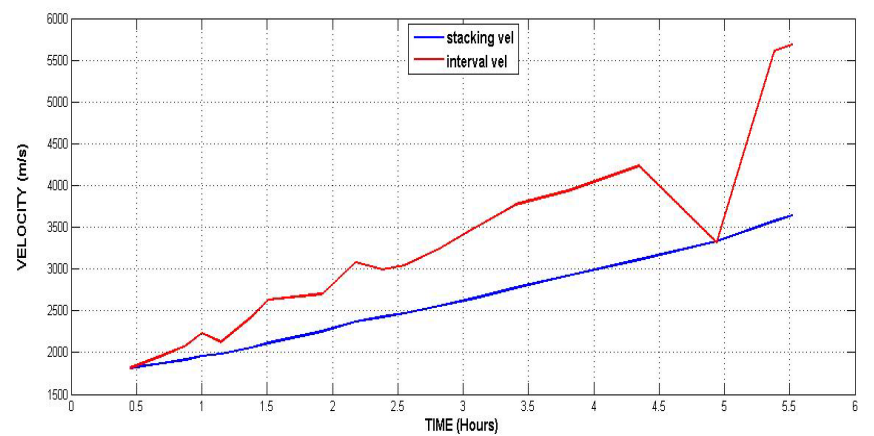

CDP 1114

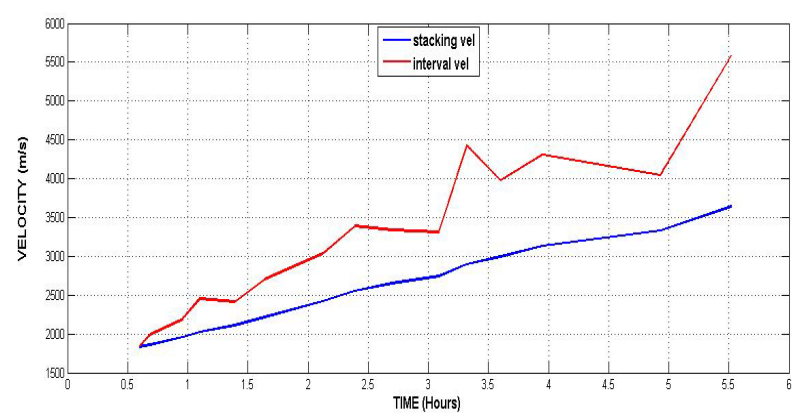

CDP 1162

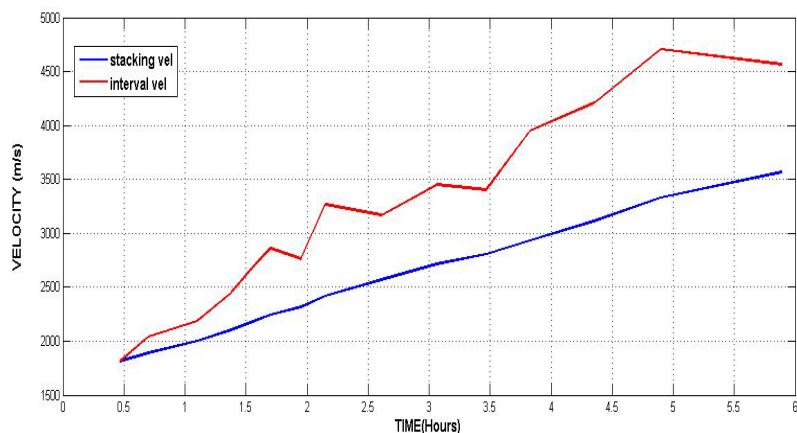

Figure 7. The variation of offset time with stacking and interval velocities for different CDPs.

\section{Conclusions}

The application of VELCOM program successfully removed the curvature of the reflection data and gave the best possible stack after processing. With the true interval velocities of layers correctly obtained, interpreters can successfully locate the actual position of hydrocarbon subsurface. For the interpreter, the interval velocity is the target of any form of velocity analysis. It helps predict the actual presence and locate the actual position of hydrocarbon subsurface. Also, if shear wave velocity is 
available, interpreter will have enough information in knowing the porosity and permeability of the formation.

\section{Acknowledgements}

The authors are grateful to the Shell Petroleum, Port Harcourt, Nigeria for making their seismic data available for analysis and the Companie Generale de Physique for the access we had to their software for the processing.

\section{REFERENCES}

[1] Sheriff, R. E. and Geldart, L. P. (1995). Exploration Seismology, 2ed, Cambridge University Press.

[2] Kogbe, C.A. (1976). The Cretaceous and Paleocene sediments of southern Nigeria, In Kogbe, C.A. (ed.), Geology of Nigeria,
Elizabethan press, pp. 273-282.

[3] Novelli, L. (1974). Outline of Niger Delta Geology: Proc. Well Evaluation Conference, Nigeria, 1 - 5.

[4] Short, K.C and Stauble, A.J. (1967). Outline of Geology of Niger Delta, Am. Assoc. Petroleum Geologists Bull, 51 (5): 761-779.

[5] Mascle, J., Bomhold, B.P. and Renard, V. (1973). Diapiric structures of the Niger Delta. Am. Assoc. Petroleum Geologists Bull. 57: 2672-2678.

[6] Ofoegbu, C.O. (1985). A Review of Geology of the Benue Trough, Nigeria, Journal of African Earth Sciences, 3 (3): 281-291.

[7] Reijers, T.J.A. (2011). Stratigraphy and Sedimentology of the Niger Delta. Geologos, 17(3): 133 - 162. Dio: $10.2478 / \mathrm{v} 010118-011-0008-3$.

[8] Dobrin, M.B. (1976). Introduction to Geophysical Prospecting, $3^{\text {rd }}$ Edition. McGraw-Hill, New York.

[9] Dix, C.H. (1955). Seismic Velocities from Surface Measurements, Geophysics, 20, $68-86$. 